\title{
Localization of Centriolar Appendages during Ciliogenesis
}

\section{Shubhra Majumder* and Harold A Fisk}

Department of Molecular Genetics, The Ohio State University, 484 W 12th Avenue, 216 Biological Science Building, Columbus, Ohio, USA

Human retinal pigment epithelial (RPE1) cells were serum starved for $48 \mathrm{~h}$, fixed and stained for components of centrosomes, centriolar appendages and primary cilia. The micrograph on the left is of a cell stained for the distal appendage protein Cep164 (red), hCenexin1/ Odf2 (green) that localizes proximal to Cep164, and the pericentriolar matrix (PCM) protein $\gamma$-tubulin ( $\gamma$-tub, magenta). The micrograph on the right is of a cell stained for Cep164 (green) and Acetylated-tubulin (Ac-tub, red) that marks the microtubules of both centrioles and the ciliary axoneme. DNA is shown in blue, bar is $5 \mu \mathrm{m}$, and the regions surrounded by the white boxes are digitally magnified in the insets.
RPE1 cells assemble primary cilia during serum starvation. During cilia assembly, the mother centriole that is distinguishable from the other centriole (known as 'the daughter centriole') of a centrosome due to the presence of distal and sub-distal appendages is transformed into a basal body that assembles the cilium. Images here illustrate the localization of centriolar appendage proteins at the transition zone, the region between the ciliary axoneme and the basal body, of primary cilia.
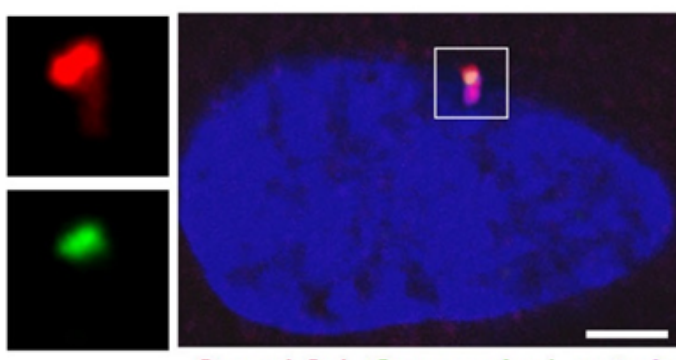

Cep164 Cenexin1 $\gamma$-tub DNA
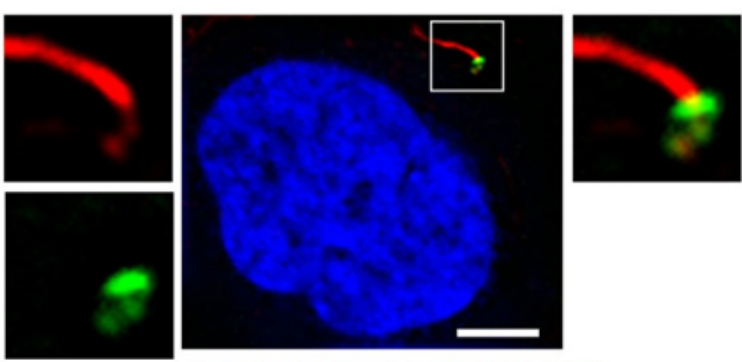

Ac-tub Cep164 DNA

Figure 1: Serum Starved RPE1 cells.

*Corresponding author: Shubhra Majumder, Department of Molecular Genetics, The Ohio State University, 484 W 12th Avenue, 216 Biological Science Building, Columbus, Ohio, USA, Tel: 6143138187; E-mail: majumder.7@osu.edu

Received May 04, 2015; Accepted May 05, 2015; Published May 07, 2015

Citation: Majumder S, Fisk HA (2015) Localization of Centriolar Appendages during Ciliogenesis. Single Cell Biol 4: i106. doi:10.4172/21689431.1000i106

Copyright: (c) 2015 Majumder S, et al. This is an open-access article distributed under the terms of the Creative Commons Attribution License, which permits unrestricted use, distribution, and reproduction in any medium, provided the original author and source are credited. 